\title{
Through the doors of deception?
}

\author{
Charles Medawar
}

Listening to Prozac. By Peter D. Kramer. Viking: 1993. Pp. 409. \$22.50. To be published in the United Kingdom by Fourth Estate on 7 April at £16.99.

If all goes well I will write an essay on it and I expect it will win its place in therapeutics, by the side of morphium and superior to it. I have other hopes and intentions about it. I take very small doses of it regularly against depression . . . and with the most brilliant success.

FREUD always denied that his enthusiastic advocacy for "this magical drug" was ill-judged, but his peers soon concluded otherwise and he was roundly criticized for it. Freud not only believed that cocaine was a miracle drug; he had also hoped that by revealing this truth he would secure professional advancement and wealth. At first he saw no risk of addiction to cocaine; later he reasoned that any such problem would signal some personality problem rather than any defect of the drug. Accordingly, the young Freud pressed cocaine on patients, family, colleagues and friends, persuading even his official biographer that, "looked at from the vantage point of our present knowledge, he was rapidly becoming a public menace".

Years before this Freudian skid - and ever since - doctors have prescribed a virtually uninterrupted succession of addictive drugs for anxiety and the like, each time in the mistaken belief that the drugs would not cause dependence or that it was the patient's fault if they did. For years, morphine was used to treat opium addiction, and heroin was later routinely used to treat addiction to cocaine. This list is long: it now includes numerous barbiturates and related drugs and extends beyond even the benzodiazepines (such as Valium and Librium), still widely prescribed today.

It took more than 25 years to establish how addictive the benzodiazepines really are. Even a decade after the introduction of Librium, its manufacturers could get away with a centre-spread advertisement in a learned journal headlined: "Whatever the diagnosis - Librium" (British Medical Journal, 1 March 1969). And there were positive streams of anecdotal clinical evidence to prove it:

The effect of Librium on the symptom of excessive withdrawal and tension (excessive control) is remarkable, and may be illustrated by the description volunteered by one patient, a teacher: "I think it is miraculous. I was feeling outgoing. The effect was so liberating that I felt excited and very outgoing . . I I would walk into the class completely unprepared and end up well. It made me become less involved with myself and my state of mind was outgoing" [Toll, N. Disorders of the Nervous System, 264-6, March 1960].
My reading of Dr Peter Kramer's book about Prozac - the antidepressant drug fluoxetine - has been much influenced by this historical background. So far as one can tell from controlled clinical trials, Prozac is about as effective as other antidepressant drugs, yet Kramer claims that with many of his patients he has had sensational results. In the United States,

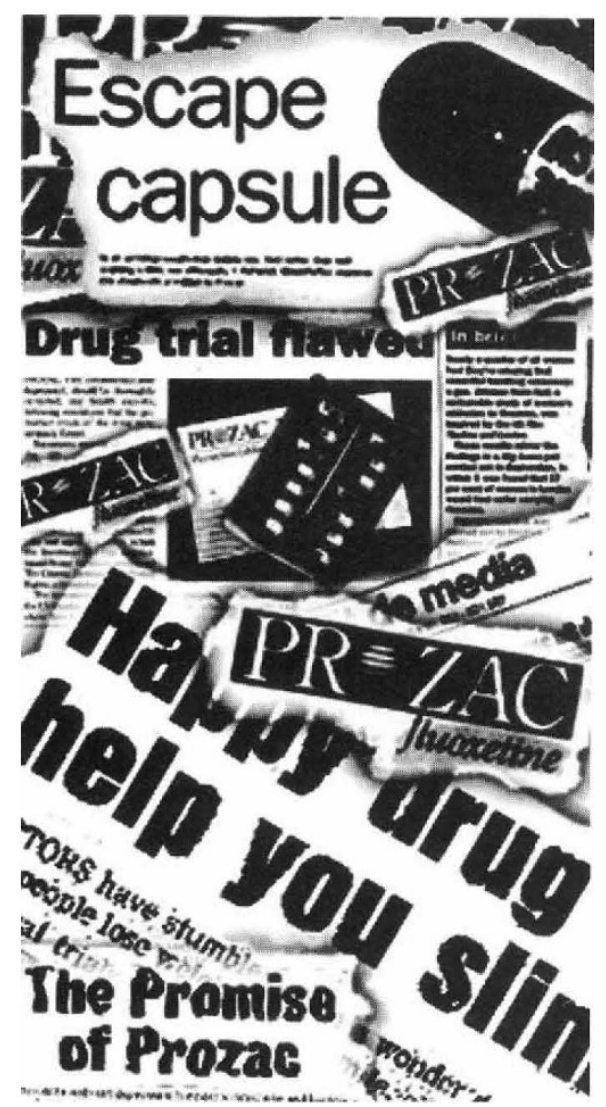

Hyped-up - Prozac makes the headlines.

the book has become a huge bestseller and Prozac is now a craze; some five million Americans take the drug and the numbers are rising. Working quite independently of the manufacturers, Kramer must have sold far more Prozac with his book than they could have ever hoped to achieve alone: sales now exceed $\$ 1.2$ billion per year.

Kramer's book is based on anecdotes, most of which detail the experience of about a dozen of his patients; they found not so much that Prozac cured them of illness but that it transformed their lives. The word 'health' is not to be found in the index; this book is about the alleged propensity of fluoxetine to produce in some unspecified proportion of fairly healthy users increased faith in themselves; greater hope for professional, social and personal growth; and love of life. In a nutshell: "since you only live once, why not do it as a blonde? Why not as a peppy blonde?"

The explanation for the intriguing title is Kramer's view that fluoxetine can be used both to understand and then to shape traits of character, perhaps achieving at a stroke what followers of Freud might take years to achieve. But make no mistake, this book is not about "Listening to Prozac" but about catching the drift of a somewhat beamed-up psychiatrist. Kramer's statement of his credentials hints of keen identification with the world of Star Trek and Captain Kirk:

My quest has led me deep into territories whose results inform my clinical work but whose culture and customs are foreign: cellular physiology, pharmacology, history of medicine, animal ethology, medical ethics, descriptive psychiatry" [p.xix].

And this seems a heavy boast considering the lightweight quality and style of what Kramer really has to offer. The nub of his evidence on the effects of Prozac on his patients' lives is not science but soap:

"Three dates a weekend," Tess told me. "I must be wearing a sign on my forehead!" Within weeks of starting Prozac, Tess settled into a satisfying dating routine with men" [p.7].

Now she strode forward and gave me a bold "Hello." I responded, and she said, "I've changed my name, you know.". . . She had, I saw, the bright and open manner that had brought Tess so much social success. "Yes," she continued, "I call myself Ms. Prozac" [pp. 11-12].

"People on the sidewalk ask me for directions!": I have since heard this identical report from other people on Prozac [p.320].

This is the content and tone that have made the book a commercial success, although its credibility has been bolstered with a fair amount of more baffling material besides. Psychobabble accounts for part of it and Kramer also makes a determined attempt to explain some of the very little that is known about the chemical niceties of brain function in the regulation of mood and mind.

Moral and social issues are raised too, and centrally this question: is it ethical to treat someone who is not ill with a drug that makes them feel "better than well"? This, to my mind, is alarmingly disingenuous: Kramer clearly has miraculous transformations in mind, and proudly coins the term "cosmetic psychopharmacology" to prove it. He must have known that to write so seductively about a feelgood drug would stimulate mass demand and inevitably some misuse.

We do not yet know enough about this drug, and it will be years before we do. Fluoxetine was tested in controlled trials 
lasting only a few weeks, and was licensed only a few years ago on the strength of results that gave no hint of the easy trips to which Kramer refers. (I would not be surprised if some passages evoked in cannabis users a sense of déjà vu.)

It certainly will not do to declare: "It is not addictive - patients do not crave Prozac, and there is no known withdrawal syndrome" (p. 311). The clear message of history is to beware of any explosive, mass demand for a psychoactive drug, and never to forget that patients don't crave so long as doctors readily prescribe. It is also worth noting that there is still profound confusion over the differences in meanings of 'dependence' and 'addiction', despite clarification from the World Health Organization 30 years ago. The Royal Colleges of Psychiatrists and General Practitioners still insist that "antidepressants are not addictive" and that people are "mistaken" in thinking they can cause dependence (RCP/RCGP Defeat Depression Campaign Release, 1992), despite evidence that most antidepressants (unlike cocaine) are associated with a withdrawal syndrome. This is why the British National Formulary recommends that when patients stop taking these drugs, "reduction in dosage should preferably be carried out gradually over a period of about four weeks".

What the Royal Colleges are really saying is that antidepressants have no great market street value and do not lead to overt drug-seeking behaviour. But this does not properly address the concern that both doctors and patients may misinterpret withdrawal symptoms as recrudescence of disease, and then see this as evidence of the effectiveness of the drug and of the need to continue treatment with it. This is what happened with the benzodiazepines, barbiturates and all the rest, and it led to dependence on a grand scale.

And the risk would be greater with drugs such as fluoxetine, which are only slowly cleared from the body. This means that withdrawal symptoms tend to peak long after the drug is stopped and therefore that the drug would be less likely to be identified as their cause. In any case, if one defines 'dependence' simply as 'druginduced drug consumption', one would never conclude from Kramer's evidence that fluoxetine is a drug that anyone might take or leave at will:

We lowered the dose of medicine, and two weeks later Julia called to say that bottom had fallen out: "I'm a witch again." She felt lousy - pessimistic, angry, demanding . and then she used the very words Tess had used: "I don't feel myself.". . . Julia resumed taking the higher dose of Prozac. Within two weeks, she felt somewhat better; after five weeks, she was "almost there again," with many more good days than bad. She said work had been torture on the lower dose of medicine [pp. 29-30].
Bearing in mind that "Prozac has not been systematically studied, in animals or humans, for its potential for abuse, tolerance, or physical dependence" (Physicians Desk Reference, 4th edn, 943-6 (Medical Economics, Oradell, New Jersey, 1993)), it would be folly not to undertake searching enquiries into how Prozac is used and misused and to what effect. Some users clearly do benefit, although in pre-marketing trials one in seven patients had to quit because of adverse effects, most commonly psychiatric (ibid.). The broad spectrum of these unwanted symptoms is worrying, with some people becoming badly agitated and hyped-up, and others brought right down; in extreme cases, manic psychoses and suicide have been mentioned as real risks. In a mass market there will certainly be many casualties and much more could be done to prevent them.

Then there are uncertainties about dosing. Noting that patients responded in the wide range of $5-80 \mathrm{mg}$ per day, the Swedish and Norwegian authorities in 1991 refused to give Prozac a licence - because it was supplied only in a $20-\mathrm{mg}$ size. Kramer has little to say about doses, and where he does he seems unduly relaxed:

[Gail] asked whether I could raise the dose of Prozac so she would feel comfortable applying for the post. I did not know whether a different dose would have a different effect, but I saw no reason not to try. She took extra Prozac, and she applied for the promotion. She was eventually turned down, but she was able to take the rebuff in stride [p.94].

Who knows, Prozac may turn out to be the triumph of benefit over risk. In the meantime, it might be safer to regard this book as an object lesson in how not to evaluate a drug, and as a dire if inadvertent warning that products such as Prozac threaten to consume us all. We must not forget that the greatest mistakes in medicine tend to be made not because doctors don't know enough, but when they behave as if they do.

Charles Medawar is at Social Audit Ltd, PO Box 111, London NW1 8XG, UK.

\section{Ne'er the twain shall meet}

\section{RyanJ. Huxtable}

The Billion Dollar Molecule: One Company's Quest for the Perfect Drug. By Barry Werth. Simon and Schuster: 1994. Pp. 445. \$25.

Music lessons in my high school usually consisted of chanting "R-H-Y-T-H-M spells rhythm" or "Every Good Boy Deserves Fruit". On the rare occasions we had actual music, it was always something in a minor key, such as the song 'Behold a giant am I, aloft here in my tower'. This song is emblematic of the traditional academic, renowned in his field, living a monkish existence above the temporalities of common humanity. But, as another song has it, the times they are a-changing. Knowledge in US universities is now valued not for such unquantifiable attributes as 'for its own sake' but for the market price it carries. Forget the leather elbow patches on the smoky jacket. In the bright new world of managed scholarship and technology-transfer offices, the leather is on the briefcase of the professor raising venture capital for his biotech company.

This is the story of the collusions and clashes between industrial and academic scientists involved in a small company's search for a better immunosuppressant. A drug that can dislocate the biological system that asserts identity, distinguishing 'me' from 'not-me', is a valued product in an alchemical world of organ transplants. Hearts, lungs, bits of brains and even complete viscera are, in the argot of the trade, harvested from one individual and incorporated into another. The surgery is straightforward. Transplantation, howev$\mathrm{er}$, is vitiated by tissue rejection in the recipient. The alkahest that dissolves identity between donor and recipient, allowing the transplant to remain unrecognized, is an immunosuppressant. One immunosuppressant, cyclosporin, was isolated from a fungus growing in the wastes of arctic Norway. Another, FK-506, came from a mountainside in Japan. Both have numerous side effects. But suppose you engineered a drug specifically for the receptor that these immunosuppressants act on...?

The classic way of developing a drug once was to go to nature. That gave us morphine, vincristine, digitalis and taxol. Then the Faustian hubris of our species led us to think that whatever nature could do, we could do better. So we synthesized thousands of compounds more or less at random and tested them for drug activity. That gave us sulphonamides, INH, Salvarsan and propranolol. Then came Joshua Boger, founder of Vertex. His company would use a third, new way, of developing drugs: it would design them. Structure-based design would identify what a drug had to do and where it had to bind, and then the appropriate molecule could be custom designed. Line the balls up, tap gently with the cue and bingo! Illimitable largesse - the billion dollars of the book's title - would pour into the 